\title{
Impact of allergic rhinitis and specific subcutaneous immunotherapy on peripheral blood basophils of patients sensitized to Dermatophagoides pteronyssinus
}

Ana Lopes ${ }^{1}$, Patrícia Azenha ${ }^{2}$, Cristina Teodósio ${ }^{3}$, Maria Inácio ${ }^{1}$, Isabel Silva ${ }^{1}$, Graça Loureiro ${ }^{4}$, António Martinho ${ }^{1}$, António S Luís ${ }^{4}$, Hélder Trindade ${ }^{1}$, Celso Pereira ${ }^{4}$ and Artur Paiva ${ }^{1,2^{*}}$

\begin{abstract}
Background: Basophils are important effectors cells in allergic rhinitis (AR) since they are involved in immunoglobulin (Ig) $\mathrm{E}$ - mediated inflammation and in the release of pro-inflammatory mediators. Specific subcutaneous immunotherapy (SCIT) provides clear immunologic modulation in some immune cells, however its systemic effects on basophils are not well known.

Methods: Peripheral blood (PB) samples from 43 patients with allergic rhinitis mono-sensitized to Dermatophagoides pteronyssinus (Dpt) [33 of them under SCIT with allergoid Dpt extract, in maintenance dose (SCIT), with evaluation just before SCIT injection (SCIT-T0) and 4 hours later (SCIT-T4) and the other 10 Dpt allergic patients never having, in the past, undergone specific immunotherapy treatment (NSIT)], and 15 healthy age- and gender-matched controls $(\mathrm{HG})$, were analyzed. For each sample, the total (t-lgE) and specific $\lg \mathrm{E}(\mathrm{s}-\mathrm{lg} \mathrm{E})$ was performed, as well as, the relative frequency and absolute number of PB basophils and receptor-bound IgE and IgG expression were evaluated by flow cytometry and the Histamine N-methyltransferase (HNMT) and tryptase a/B1 (TPSAB1) gene expression was assessed by real-time PCR.
\end{abstract}

Results: Higher levels of receptor-bound IgE were observed in SCIT patients, which are correlated with the levels of serum t-lgE and s-lgE, whereas no significant differences were observed for receptor-bound lgG. Regarding HNMT mRNA expression, significantly lower expression levels were detected in AR patients compared to HG, independently of type of therapy. Moreover a negative correlation was found between HNMT gene expression and time under SCIT. Conversely, tryptase gene expression was significantly up-regulated in NSIT when compared to HG; however in SCIT patients, tryptase gene expression was significantly decreased than in NSIT patients. No differences were found for any parameter between SCIT-T0 and SCIT-T4 with exception of a transient increased expression of tryptase in SCIT-T4.

Conclusion: PB basophils from patients with AR show altered functional features, which seems to be influenced by SCIT, suggesting that these cells could be useful to clarify the SCIT triggered mechanisms at a systemic level.

Keywords: Allergic rhinitis, Dermatophagoides pteronyssinus, Basophils, Histamine N-methyltransferase, Tryptase, Specific subcutaneous immunotherapy

\footnotetext{
* Correspondence: apaiva@histocentro.min-saude.pt

'Blood and Transplantation Center of Coimbra, Portuguese Institute of Blood and Transplantation, Edifício São Jerónimo, 4 Piso, Praceta Mota Pinto,

3001-301, Coimbra, Portugal

${ }^{2}$ College of Health Technology of Coimbra, São Martinho do Bispo, 3046-854,

Coimbra, Portugal

Full list of author information is available at the end of the article
} 


\section{Introduction}

Rhinitis is a heterogeneous group of nasal disorders characterized by one or more symptoms, including, sneezing, itching, rhinorrhea, and/or nasal congestion, which ultimately have a negative impact on the patient's quality of life. Rhinitis can be caused by nonallergic factors like infection, hormones or others [1,2], although approximately 50\% of all cases are allergy-related. This later variant of the disease - allergic rhinitis (AR) - is the most common allergic condition affecting $10 \%$ to $40 \%$ of the world population, depending on the geographical setting [3].

Several factors may specifically contribute to the pathophysiology of AR, including the local synthesis of immunoglobulin (Ig) E in nasal mucosa, the up-regulation of Th2 cytokines or the alteration in the number of regulatory $\mathrm{T}$ (Treg) cells [4]. However, as an allergic process, most symptoms arise as a consequence of local inflammation induced by an IgE-mediated immune response to specific allergens such as pollens, molds, animal dander and dust mites [5], ultimately leading to the local accumulation of an inflammatory cell infiltrate composed of different cells including $\mathrm{T}$ cells, eosinophils, mast cells and basophils [6,7]. As a result of the cross-linking of IgE on basophils and mast cells by allergens, several mediators (e.g. leukotrienes, prostaglandins, tryptase and histamine) are released contributing to the development of the inflammatory response and the symptoms [8].

Basophils along with eosinophils and mast cells, are the main effector cells in this allergic inflammation process, but unlike the later cells that reside in the tissue, basophils circulate in the peripheral blood and selectively migrate to sites of inflammation $[9,10]$. Additionally, their active participation in the pathogenesis of allergic inflammation has been widely supported in the literature through the release of preformed and newly generated mediators like leukotriene $\mathrm{C}_{4}$, major basic protein, IL-4, IL-13, tryptase and histamine [11-15].

Among these molecules, histamine is the primary mediator involved in the development of symptoms of AR in both early and late-phase reactions, being also able to activate immunocompetent cells, including $\mathrm{T}$ lymphocytes influencing the Th1/Th2 balance towards a Th2 polarization [16]. The regulation of the production and activity of this mediator is performed by its inactivation and/or transport into cells to remove an excess amount of histamine in extracellular space. The major routes of histamine inactivation are catalyzed by two main catabolic pathways: methylation by oxidative deamination by diamine oxidase (DAO) and histamine N-methyltransferase (HNMT), which has been suggested to play a critical role in the degradation of histamine in the airway $[17,18]$.

Specific subcutaneous immunotherapy (SCIT) has been widely reported to show clinical effectiveness in the treatment of allergic rhinitis and asthma [19], providing a long- term remission of allergic symptoms and reducing the development of new sensitization to other allergens $[20,21]$. The mechanisms by which clinical responses are achieved have been extensively described and include a decrease in basophils and mast cell activation within the affected tissues, induction of $\mathrm{T}$ cells anergy, generation of Th1 and Treg cells, decrease of allergen-specific IgE antibody levels, associated with the production of allergenspecific $\operatorname{IgG}_{1}$ and $\operatorname{IgG}_{4}$ antibodies (IgG "blocking activity") and induction of the production of non-inflammatory IgA antibodies by B cells [20,22-24].

Interestingly, despite the influence of AR on effector cells, like basophils, and the impact of SCIT therapy within the nasal mucosa, are relatively well known, the potential systemic effect of AR and SCIT on PB basophils remains largely unknown.

In this context, we mainly aimed to evaluate the effects of AR and SCIT on PB basophils. For this propose we analyzed the frequency of $\mathrm{PB}$ basophils, expression of receptor-bound IgE and IgG on the membrane and the mRNA expression of basophil mediator-related genes (histamine N-methyltransferase and tryptase) in patients with monosensitization to Dermatophagoides pteronyssinus (Dpt) submitted to SCIT (before and 4 hours later the allergen injection) and compared them to AR patients who were never submitted to SCIT and to healthy individuals. Moreover we looked for a possible correlation between those results with total (t-IgE) and specific IgE (s-IgE) in the serum and with time under SCIT.

\section{Materials and methods \\ Patients}

Overall, 43 AR patients were included in this study, all of them with at least 2 years of perennial symptoms, wheal $3 \mathrm{~mm}$ larger than the negative control related to histamine response and the values of serum specific IgE at least class 2 (CAP). 33 patients with AR mono-sensitized to mites under active maintenance SCIT treatment with allergoid Dpt extract Depigoid (Leti, Madrid, Spain) with monthly maintenance dose of $0.5 \mathrm{ml}$ volume (Der p $1=7.2 \mu \mathrm{g} / \mathrm{ml}$ ) (SCIT) (age: $30 \pm 11$ years; sex: 19 males and 14 females) (Table 1). The diagnosis was established based on clinical symptoms, positive skin prick tests, serum specific IgE assay, and positive nasal challenge test.

Exclusion criteria included the following: pregnancy, pediatric group, mental diseases or other comorbidities, chronic medication and/or active infection and inflammation. At the moment of the treatment implementation a diagnosis of persistent moderate/severe rhinitis, ARIA Classification [25], and the presence of concomitant mild persistent controlled asthma, GINA Classification [26] was not an exclusion criteria. When included in the study, all patients presented clinical efficacy to the treatment, as defined by reduction of clinical score and medication 
Table 1 Clinical and laboratorial characteristics of the individuals included in the study

\begin{tabular}{|c|c|c|c|}
\hline & $\begin{array}{c}\text { HG } \\
(n=15)\end{array}$ & $\begin{array}{c}\text { NSIT } \\
(n=10)\end{array}$ & $\begin{array}{c}\text { SCIT } \\
(n=33)\end{array}$ \\
\hline \multicolumn{4}{|l|}{ Age (years) } \\
\hline Mean \pm SD & $29 \pm 10$ & $26 \pm 7$ & $30 \pm 11$ \\
\hline Range & $(18-38)$ & $(19-38)$ & $(17-61)$ \\
\hline \multicolumn{4}{|l|}{ Gender } \\
\hline Male & $53 \%(n=8)$ & $30 \%(n=3)$ & $58 \%(n=19)$ \\
\hline Female & $47 \%(n=7)$ & $70 \%(n=7)$ & $42 \%(n=14)$ \\
\hline \multicolumn{4}{|l|}{ Clinical parameters } \\
\hline Time from disease onset (years) & NA & $10 \pm 7$ & $12 \pm 8$ \\
\hline Time of SCIT (months) & NA & NA & $28 \pm 13$ \\
\hline Presence of Asthma & NA & $40 \%(4 / 10)$ & $43 \%(13 / 30)$ \\
\hline \multicolumn{4}{|l|}{ Laboratorial parameters } \\
\hline Serum total $\lg E(t-\lg E)(\mathrm{kU} / \mathrm{L})$ & NA & $295 \pm 231$ & $514 \pm 787$ \\
\hline Serum specific $\lg E(s-\lg E)\left(k \cup_{A} / L\right)$ & NA & $48 \pm 27$ & $45 \pm 35$ \\
\hline
\end{tabular}

$N A$, Not applies. The results were given by mean \pm standard deviation.

consumption such as inhaled steroids and relief medication (oral anti-histamines). In all of them the induction phase was achieved after 6 doses of weekly injection, followed by 1 injection every 4 weeks as a maintenance dose for a minimum of 12 months. For this particular group of patients an evaluation before SCIT injection (SCIT-T0) and 4 hours later (SCIT-T4) was performed, according the time of the beginning of the late phase of allergen inflammatory response [27].

Additionally, a control group (NSIT) of 10 respiratory allergic patients monosensitized to mites who had not submitted, in the past, to specific immunotherapy, and that displayed the same clinical profile and the exclusion criteria as the SCIT group (age: $26 \pm 7$ years; sex: 3 males/7 females) was studied (Table 1). Treatment in this group of patients was implemented according to the recommended guidelines (oral systemic anti-histamines, nasal and bronchial corticosteroid therapy and bronchodilators for patients with asthma). Of note, all the analyses were performed during a period of clinical stabilization in both AR groups.

\section{Healthy individuals group}

Another control group was selected composed by 15 healthy individuals (HG) (age: $29 \pm 10$ years; sex: 8 males/7 females). These participants were required to complete a brief questionnaire regarding previous or current medical conditions. Inclusion criteria for this group included absence of autoimmune and allergic diseases, as well as, of an active infection. Additionally, only individuals who were not undergoing treatment with immunomodulatory drugs for any known conditions were included in this control group.

\section{Samples}

PB samples from each individual were collected into K3EDTA, serum tubes (Becton Dickinson (BD) Bioscience, San Jose, CA, USA) and PAXgene Blood RNA tubes (PreAnalytiX GmbH, Switzerland).

\section{Ethical standards}

The study protocol was approved by the Ethical Committee from Coimbra 185 University Hospital. All participants gave and signed an informed consent form, and the principles of Helsinki Declaration were respected.

\section{Determination of total and specific IgE}

Quantitative determination of serum t-IgE was performed using nephelometry method. Total IgE concentration $(\mathrm{kU} / \mathrm{L})$ was determined comparing the results with the calibrators provided.

Serum s-IgE to Dermatophagoides pteronyssinus was determined using the ImmunoCAP fluorescence enzyme immunoassay technique (Phadia, Uppsala, Sweden). To evaluate the test results, the response from the patients samples was converted to concentrations using a calibration curve. The range of measurements was 0.35 to $100 \mathrm{KU}_{\mathrm{A}} / \mathrm{L}$.

\section{Multiparameter flow-cytometry immunophenotypic studies of PB basophils}

Identification and characterization of $\mathrm{PB}$ basophils was performed using a anti-IgG conjugated with flourescein isothiocyanate (clone: G18-145, BD Bioscience), anti- IgE conjugated with phycoeritrin (clone: BE5, EXBIO Praha, Vestec, Czech Republic), anti-HLA-DR peridinin chlorophyll protein cyanine 5.5 (clone: G46-6, BD Bioscience), 
anti-CD123 allophycocyanin (clone: AC145, Miltenyi Biotec; Bergisch, Gladbach, Germany) and anti-CD45 krome orange (clone: J.33, Beckman Coulter, Brea, CA, USA) combination of monoclonal antibodies (mAb).

For sample processing, two washing steps using phosphate-buffered saline (PBS) (Gibco BRL-life Technologies, Vienna, Austria) were performed before staining, in order to remove the free immunoglobulins present in the plasma samples. For sample staining, a direct immunofluorescence technique was used. Briefly, mAb were added to $200 \mu \mathrm{L}$ of $\mathrm{PB}$ and were incubated for $15 \mathrm{~min}$ at room temperature in darkness. After this incubation period, a lyse-and-then-wash protocol was followed: incubation with $2 \mathrm{~mL}$ of FACS Lysing Solution (BD Bioscience) diluted 1:10 (vol/vol) for $10 \mathrm{~min}$ followed by a washing step with $2 \mathrm{~mL}$ of PBS (Gibco BRL-life Technologies). Cells were ressuspended in $0.5 \mathrm{~mL}$ of PBS (Gibco BRL-life Technologies) before acquisition in flow cytometer.

\section{Flow cytometry data acquisition and analysis}

Data acquisition was performed in a FACSCanto II flow cytometer (BD Bioscience) using the FACSDiva software (BD Bioscience).

Basophils were identified according to their high expression of CD123 in absence of HLA-DR and by their moderate CD45 expression, dimmer than lymphocytes [28]. The relative amount of receptor-bound IgE and IgG was determined based on their mean fluorescence intensity (MFI).

Absolute numbers were calculated using a dual platform methodology (flow cytometry and hematological cell analyser). For data analysis the Infinicyt ${ }^{\text {TM }}$ software, V.1.5 (Cytognos SL, Salamanca, Spain) was used.

\section{Gene expression analysis}

For the analysis of histamine N-methyltransferase (HNMT) and tryptase $\alpha / \beta 1$ (TPSAB1) gene expression, whole peripheral blood was collected in a PAXgene Blood RNA Tube (PreAnalytiX) and total automated RNA purification was performed in QIAcube (Qiagen, Hilden, Germany).

RNA integrity and quantification were performed using a 6000 Nano Chip Kit in an Agilent 2100 bioanalyzer (Agilent, Walbronn, Germany). For quantitative reversetranscription polymerase chain reaction (RT-qPCR), one microgram of RNA was reverse transcribed with iScript ${ }^{\text {TM }}$ Reverse Transcription Supermix (Bio-Rad, Hercules, CA, USA) according to the manufacturer's instructions.

Relative quantification of gene expression was performed by real-time PCR using the LightCycler 480 II thermocycler (Roche, Basel, Switzerland). Normalization for gene expression quantification was performed with a geNorm Housekeeping Gene Selection Human Kit (Primer Design, Southampton, UK) and geNorm software (Center for Medical Genetics, Ghent University Hospital, Ghent,
Belgium), in order to select optimal housekeeping genes for this study [29].

Real-time PCR reactions performed using specific QuantiTect Primer Assays (Qiagen) with optimized primers for HNMT (QT00009282) and TPSAB1 (QT01670298) and endogenous controls as beta-actin (QT01680476) and glyceraldehyde 3-phosphate dehydrogenase (QT01192646) with QuantiTect SYBR Green PCR Kit Gene expression (Qiagen), according to the manufacturer's instructions. Reactions were performed with the following thermal cycling profile: $10 \mathrm{~min}$ at $95^{\circ} \mathrm{C}$, plus 50 cycles of $10 \mathrm{~s}$ at $95^{\circ} \mathrm{C}, 20 \mathrm{~s}$ at $55^{\circ} \mathrm{C}$, and $30 \mathrm{~s}$ at $72^{\circ} \mathrm{C}$. Quantitative real-time PCR results were analyzed with LightCycler 480 software (Roche) and quantification was performed using the qBasePlus software package (Biogazelle, Zulte, Belgium).

\section{Statistical analyses}

Statistical evaluations of data were performed using the non-parametric Mann-Whitney $U$ test for independent variables. Wilcoxon signed-rank test was used to compare related groups and a Spearman's rank correlation was applied to detect the association between different parameters. Results were expressed as median with interquartile range. All statistical analyses were performed using Statistical Package for Social Sciences IBM SPSS 20 (IBM, Armonk, NY. USA) and Graphpad Prism version 5 (GraphPad Software, San Diego, CA, USA). Differences were considered to be statistically significant when the $p$ value was less than 0.05 .

\section{Results}

\section{Relative and absolute quantification of PB basophils}

The relative frequency and absolute number of $\mathrm{PB}$ basophils were similar among the four studied groups (Table 2). Of note, no significant association was found, both for the frequency and absolute number of $\mathrm{PB}$ basophils with the time under SCIT (data not show).

\section{Serum total and specific IgE levels}

Slightly lower total serum IgE ( $t-I g E)$ levels were found in NSIT patients when compared with the SCIT patients, although not reaching statistical significance. Conversely, no differences were observed between the two AR groups regarding serum specific IgE (s-IgE) levels (Table 1).

\section{Expression of receptor-bound IgE and IgG on the membrane of PB basophils}

Receptor-bound IgE expression was significantly increased, and more heterogeneous, in the SCIT patients, compared with both HG and NSIT (Figure 1a). In line with this observation, a significant association was found between serum t-IgE and s-IgE levels and receptor-bound IgE expression, thus patients with higher serum t-IgE 
Table 2 Relative frequency and absolute cell number of circulating peripheral blood basophils in the studied groups

\begin{tabular}{lcccc}
\hline & HG & NSIT & SCIT-T0 & SCIT-T4 \\
\hline Relative frequency (\%) & 0.44 & 0.40 & 0.49 & 0.39 \\
& $(0.27-0.74)$ & $(0.25-0.67)$ & $(0.17-0.85)$ & $(0.17-1.1)$ \\
Absolute number $(\mathrm{cell} / \mu \mathrm{L})$ & 34 & 36 & 41 & 38 \\
& $(21-70)$ & $(17-56)$ & $(11-70)$ & $(15-97)$ \\
\hline
\end{tabular}

Differences were considered statistically significant when $p<0.05$. The Mann-Whitney U test used to compare between HG, NSIT, SCIT [evaluation before Dpt injection (T0) and 4 hours late (T4)]. Wilcoxon signed-rank test was used to compare SCIT-T0 versus the SCIT-T4 group. The results were given by median with interquartile range.

levels and/or s-IgE levels also showed higher IgE receptorbound levels on basophil membrane (Figure 2).

Regarding receptor-bound IgG, no significant differences were detected among the studied groups, with AR patients showing expression levels similar to healthy individuals. Nevertheless, NSIT patients showed a very heterogeneous distribution, with a slight tendency for a higher expression compared to both HG and SCIT (Figure 1b). No differences were found for both receptorbound IgE and IgG, comparing SCIT-T0 and SCIT-T4 patients.

Furthermore, a significantly decreased ratio of receptorbound IgG and IgE was observed in SCIT patients compared to NSIT patients, independently of time after SCIT injection (Table 3).

Histamine N-methyltransferase (HNMT) and tryptase $\alpha / \beta 1$ (TPSAB1) gene expression in whole peripheral blood Overall, AR patients showed significantly lower HNMT expression levels when compared with healthy controls, which was more evident in SCIT patients. 4 hours after SCIT injection the expression of HNMT remains unchanged (Figure 3a).

Concerning tryptase gene expression significant differences were found between groups. Its expression was increased in NSIT compared to HG. On the other hand,
SCIT group showed a significant decreased of tryptase gene expression than NSIT group (Figure 3b). Despite not reaching statistical significance, in the SCIT group, tryptase gene expression showed a tendency to increase 4 hours after SCIT injection.

Effect of treatment on serum total and specific IgE, receptor-bound $\operatorname{lgE}$ and $\lg$ and HNMT and TPSAB1 gene expression levels according time

HNMT gene expression was negatively correlated $(\mathrm{p}=0.0126)$ with the time under SCIT. There was a similar also effect on TPSAB1 gene expression, although the difference did not reach statistical significance (Figure 4a, b).

Similarly, serum t-IgE and s-IgE levels had a trend to decrease over time with SCIT, however it did not reach statistical significance (Figure 4c, d). Likewise, little negative correlation and an absence of correlation were found for receptor-bound IgE and IgG expression over time with SCIT, respectively (Figure 4e, f).

\section{Discussion}

Specific immunotherapy currently represents the only treatment that modifies the natural history of allergic rhinitis [27] with proven clinical effectiveness [30]. However, despite the effects of this treatment being relatively well (a)

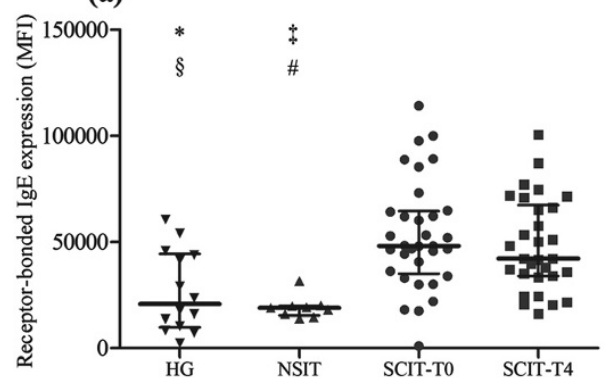

(b)

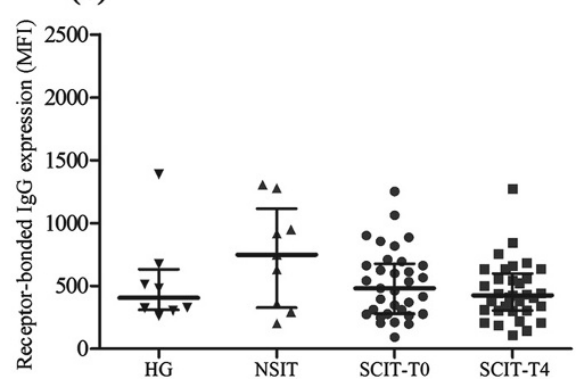

Figure 1 Receptor-bound IgE (a) and IgG (b) on PB basophils. Statistical significant differences were considered when $p<0.05$. Mann-Whitney $U$ test was used to compare between HG, NSIT, SCIT [evaluation before Dpt injection (T0) and 4 hours later the SCIT infusion (T4)]. Wilcoxon signedrank test was used to compare SCIT-T0 versus the SCIT-T4 group. The results were given by median with interquartile range. ${ }^{*} \mathrm{HG}$ versus SCIT-TO, § HG versus SCIT-T4, \# NSIT versus SCIT-T0, ‡ NSIT versus SCIT-T4. 
(a)

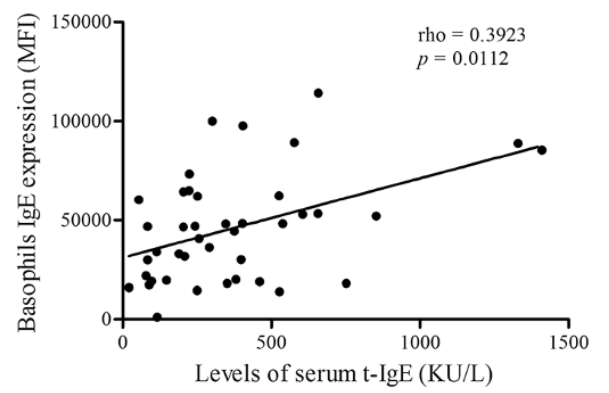

(b)

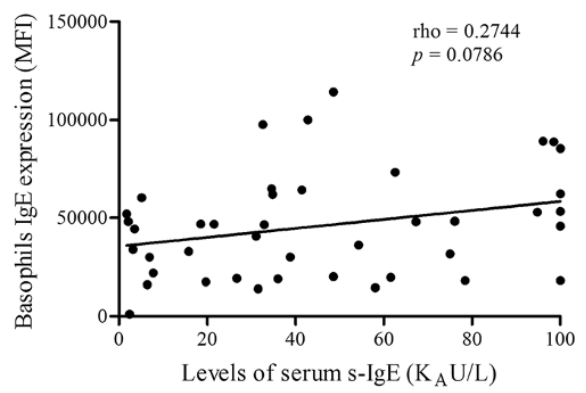

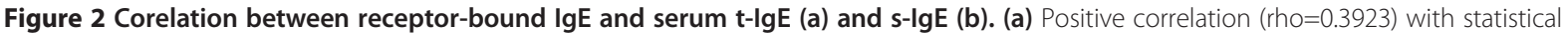
significance ( $p=0.0112$ ); (b) Absence of correlation ( $r h o=0.2744 ; p=0.0786$ ). Statistical significant differences were considered when $p<0.05$. The correlations were assessed by the Spearman's rank correlation.

described, including important immunologic changes, like a modulation of the T-cell profile, with induction of allergen-specific Treg cells, that inhibit a proliferative and cytokine response to the allergen [31,32] or a local decrease in mast cell and basophil activity [33,34]. The systemic impact of SCIT in AR patients mono-sensitized to Dpt, as well as, the repercussion of long-term treatment on the effector cells of the allergic inflammation, are widespread under research. To address this issue, in this study we analyzed the frequency and absolute number, the levels of receptor-bound IgE and IgG and the expression of mediator-related genes of circulating PB basophils from AR patients undergoing SCIT and compared them with both healthy individuals and AR patients who had never been treated with SCIT.

Overall our results suggest that, contrary to what has been described for other allergic disorders, like hymenoptera allergy [35], AR patients did not show increased PB basophil numbers. In fact, no significant differences were found for both relative and absolute basophil frequency between the different groups included in the study. These findings are probably reflecting a distinct route of exposure of the allergen in allergic rhinitis and are in line with previous studies which reported an increased frequency of basophils locally, within the airways, in allergic rhinitis [36,37]. Overall, these results further suggest that, in allergic rhinitis, the high-turnover state of the basophil

Table 3 Ratio of receptor-bound IgG and IgE on the membrane of PB basophils

\begin{tabular}{lcccc}
\hline & HG & NSIT & SCIT-T0 & SCIT-T4 \\
\hline Ratio lgG/lgE & 2.23 & 3.50 & $0.96^{*}$ & $0.98^{\#}$ \\
& $(0.56-13.57)$ & $(1.01-8.98)$ & $(0.35-2.28)$ & $(0.17-3.81)$
\end{tabular}

Differences were considered statistically significant when $p<0.05$. The MannWhitney $U$ test used to compare between HG, NSIT, SCIT [evaluation before Dpt injection (T0) and 4 hours late (T4)]. Wilcoxon signed-rank test was used to compare SCIT T0 versus the SCIT T4 group. The results were given by median with interquartile range.

*SCIT-TO versus NSIT. "SCIT-T4 versus NSIT. progenitors, resulting the short span of these cells, could balance their levels in PB circulation [38].

Regarding the amount of receptor-bound IgE on the basophils surface, increased and more heterogeneous expression levels were found in the SCIT group compared to both NSIT and HG, which showed a significant association with serum IgE levels. These observations are in agreement with previous studies by Kawakami et al. which reported a relationship between basophil expression of high-affinity IgE receptor (FceRI) and serum IgE levels, as IgE binding to its high affinity receptor leads to increased expression of FceRI [23,39-41]. Altogether, these results seem to suggest that, since patients with higher levels of serum t-IgE and s-IgE exhibited increased FceRI-bound IgE expression, the increased values for receptor-bound IgE observed in these patients are also reflecting an increased expression of FceRI on the basophils membrane. This is in line with previous studies, which described increased FceRI expression in allergic patients $[42,43]$.

Interestingly, both receptor-bound IgE expression and serum IgE levels were more heterogeneous in SCIT patients, compared to both HG and NSIT. Since it is known that allergen-specific immunotherapy leads to an initial rise, followed by a slow decline, in the level of serum IgE in allergic patients, during SIT, this high variability could reflect differences in the time that patients were undergoing SCIT. In fact, when we analysed the SCIT effect in the levels of serum $\mathrm{t}$-IgE and receptor-bound IgE expression, we observed lower levels, for both parameters, in patients under more time of SCIT [44].

Interestingly, despite it is widely known that allergenspecific immunotherapy leads to an increase in serum specific $\mathrm{IgG}_{4}$, similar levels of expression were found for all the groups included in the study regarding the amount of receptor-bound IgG on the membrane of PB basophils. This could probably due to the fact that the anti-IgG antibody used to detect bound-IgG also detects other IgG 

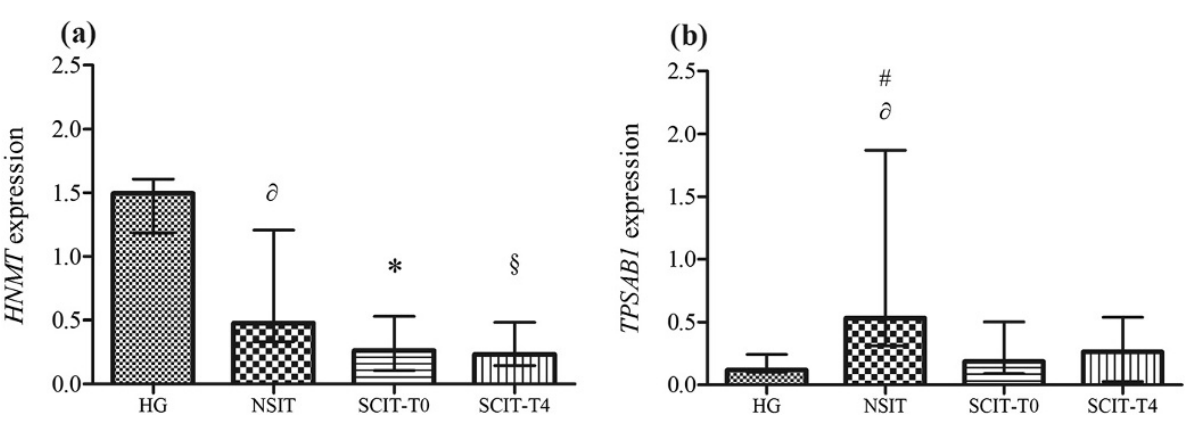

Figure 3 HNMT (a) and TPSAB1 (b) expression in whole PB. Statistical significant differences were considered when $p<0.05$. Mann-Whitney $U$ test was used to compare between HG, NSIT, SCIT [evaluation before Dpt injection (T0) and after 4 hours (T4)]. Wilcoxon signed-rank test was used to compare SCIT-TO versus the SCIT-T4 group. The results were given by median with interquartile range. * HG versus SCIT-TO, § HG versus SCIT-T4, כ HG versus NSIT, \# NSIT versus SCIT-TO.

isotypes. Further studies would be necessary, using antibodies for allergen specific IgG and its isotypes, not only in basophils, but also on other PB cells which express IgG receptors, to determine whether the increased of $\operatorname{IgG}_{4}$ serum levels are associated with a change in the membrane-bound $\mathrm{IgG}_{4}$ or other isotypes expression or, as it has been previously suggested, if the $\operatorname{IgG}_{4}$ produced during specific immunotherapy does not bind the effector cells, but protects the patients by binding the allergen, and therefore preventing its crosslinking to allergen specific $\mathrm{IgE}$ attached to effector cells or by forming IgG 4 -allergen-IgE complexes, ultimately inhibiting IgE triggering [45].

Remarkably, more than a variation in the isotype (IgE vs. IgG) or the amount of receptor-bound immunoglobulin on PB basophils, significant differences were observed amongst the different study groups regarding the expression of allergy mediator-related genes. In our study, AR patients showed significantly lower $H N M T$ mRNA expression in whole $\mathrm{PB}$, which is in line with previous studies which reported a decreased expression of this enzyme in the nasal mucosa [46]. Since no association was found between the frequency of PB basophils and therapy, this seems to indicate, that the beneficial effects of SCIT on histamine-related symptoms could be due not to a variation in the number of circulating basophils but as a result of histamine lower production. In line with this, previous studies have also reported increased expression of histidine decarboxylase in AR patients nasal mucosa, a key enzyme for the production of histamine [46], and a decreased histamine release as a result of specific immunotherapy to hymenoptera venom [47]. A relevant finding in our study was a negative correlation between time under SCIT and HNMT gene expression and since the immunotherapy could modify the histamine metabolism, the decrease of HNMT gene expression seems to be an effect of SCIT.
Additionally, histamine metabolism may not be affected directly by allergen-specific immunotherapy, as reported by Novak et al., in a model of specific venom immunotherapy, whereas an increase in the expression of histamine receptor type $2(\mathrm{H} 2 \mathrm{R})$ in basophils was observed $[48,49]$. Furthermore, this imbalance in the expression of $H 2 R$ seems to have a suppressive effect in basophil activity, associated with lower histamine production $[49,50]$.

Concerning tryptase, a more apparent modulation of the gene expression was verified, since a significant up-regulation in NSIT patients occurs compared both to healthy group and SCIT patients. This suggests that SCIT therapy, indeed, leads to a normalization of the production of this mediator, which is in accordance with previous studies by Klimer et al. who reported that the higher levels of tryptase in allergic rhinitis patients appear to be significantly inhibited by specific immunotherapy [34]. However, upon administration of SCIT, a slight increase in the expression of this mediator is observed, at least 4 hours later. This observation is in line with the increased expression of activation-related molecules in PB basophils observed immediately upon venom immunotherapy [51], and further supports the generalized recommendation for a mandatory observation period following each injection, in order to monitor the patient for the development of symptoms of type 1 hypersensitivity reaction [52]. Despite this increase after 4 hours, in our patients, SCIT therapy has led to a decrease in the tryptase mRNA expression. Noteworthy, the expression of this mast cell and basophil specific mediator, could be the result of a decrease in the release of basophil mediators [35], this decrease probably reflects the generation of allergen-specific Treg cells that are able to produce anti-inflammatory cytokines like IL-10 [33], known to reduce basophil responsiveness to IgE-mediated stimuli, through the down- 


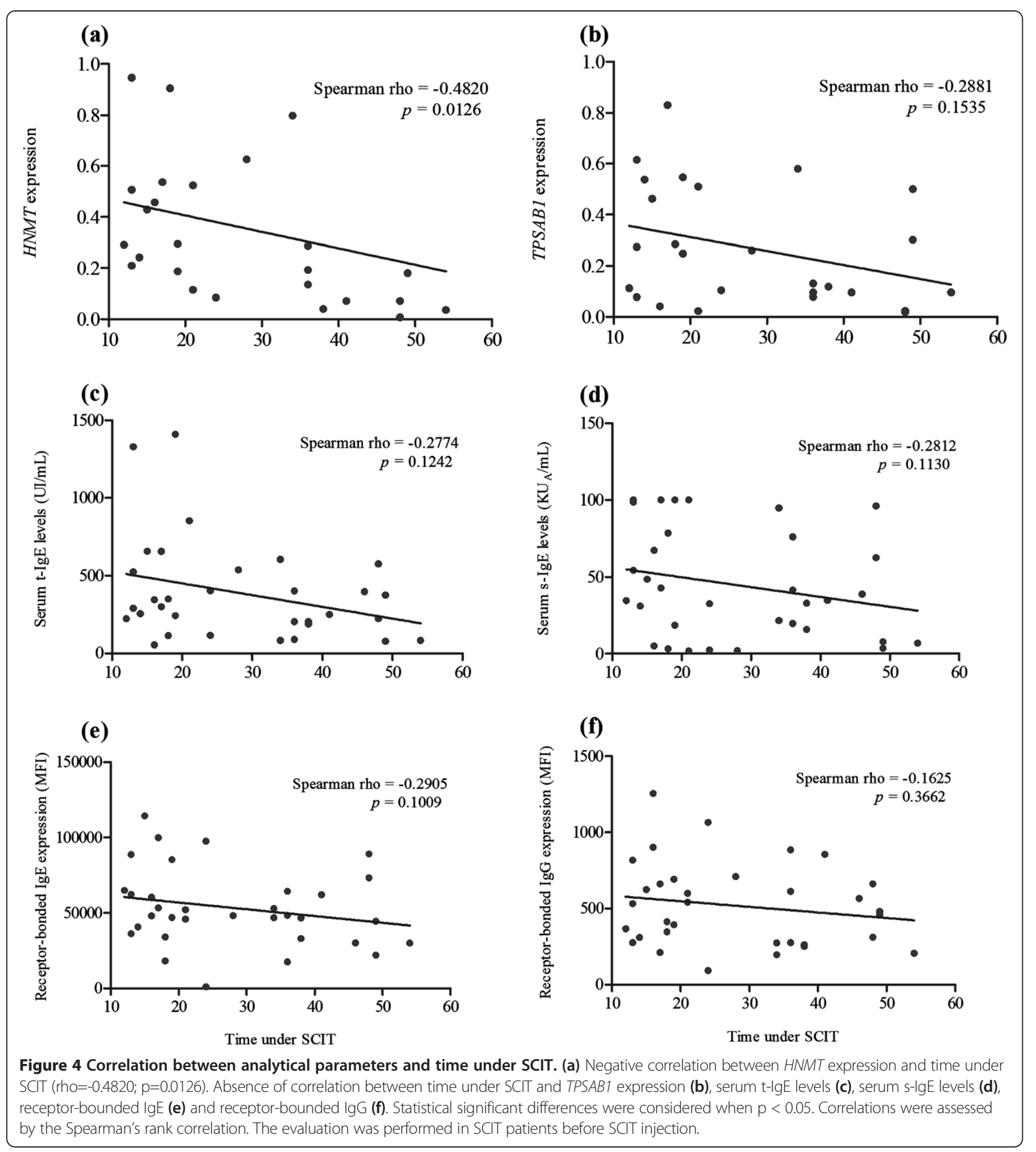

regulation of the expression of key IgE signalling molecules [53].

\section{Conclusion}

In summary, we showed that in AR patients under SCIT, peripheral blood basophils are functionally altered, with an increase of the receptor-bound IgE expression which is positively correlated with serum $\mathrm{t}-\mathrm{IgE}$ and a decrease in HNMT and tryptase gene expression, when compared to AR patients never underwent specific immunotherapy. Moreover a significant negative correlation between HNMT gene expression and time under therapy was observed.

Overall, these findings seem to contribute to a better definition of the SCIT triggered mechanisms in circulating 
basophils. However further studies, in a larger cohort of patients, would be necessary to determine the exact role that SCIT therapy could have on these parameters.

\section{Abbreviations}

AR: Allergic rhinitis; Ig: Immunoglobulin; SCIT: Specific subcutaneous immunotherapy; PB: Peripheral blood; Dpt: Dermatophagoides pteronyssinus; SCIT-TO: Evaluation just before SCIT injection; SCIT-T4: Evaluation 4 hours after SCIT injection; NSIT: Allergic patients never having undergone specific immunotherapy treatment; HG: Healthy individuals; t-lgE: Serum total IgE; sIgE: Serum specific lgE; HNMT: Histamine N-methyltransferase; TPSAB1: Tryptase $\alpha / \beta 1$; Th: T helper cells; Treg: Regulatory $T$ cells; IL: Interleukin; DAO: Diamine oxidase; ARIA Classification: Allergic Rhinitis and its Impact on Asthma; GINA Classification: Global Initiative for Asthma classification; K3-EDTA: Tripotassium ethylene diamine tetraacetic acid; mAb: Monoclonal antibodies; PBS: Phosphate-buffered saline;

FACS: Fluorescence-activated cell sorter; MFI: Mean fluorescence intensity; FceRI: High-affinity lgE receptor; H2R: Histamine receptor type 2; NA: Not applies.

\section{Competing interests}

The authors declare that they have no competing interests.

\section{Authors' contributions}

AL carried the analysis and interpretation of data, the statistical analysis and drafted the manuscript. PA and AM participated in the molecular studies. MI and IS performed flow cytometry assays. CT has been involved in manuscript revising. GL, BT and ASL contributed with provision of study material or patients. HT, CP and AP contributed to conception and designed the study protocol and given final approval of the version to be published. All authors read and approved the final manuscript.

\section{Author details}

${ }^{1}$ Blood and Transplantation Center of Coimbra, Portuguese Institute of Blood and Transplantation, Edifício São Jerónimo, 4 Piso, Praceta Mota Pinto, 3001-301, Coimbra, Portugal. ${ }^{2}$ College of Health Technology of Coimbra, São Martinho do Bispo, 3046-854, Coimbra, Portugal. ${ }^{3}$ General Cytometry Service, Cancer Research Center (IBMCC-CSIC/USAL and IBSAL) and Department of Medicine, University of Salamanca, Salamanca, Spain. ${ }^{4}$ Immunoallergology Department, University Hospital of Coimbra, 3000-075, Coimbra, Portugal.

\section{Received: 27 June 2013 Accepted: 28 September 2013}

Published: 11 October 2013

\section{References}

1. Dykewicz MS, Hamilos DL: Rhinitis and sinusitis. J Allergy Clin Immunol 2010, 125:S103-S115.

2. $\operatorname{Sin} B$, Togias A: Pathophysiology of allergic and nonallergic rhinitis. Proc Am Thorac Soc 2011, 8:106-114.

3. Montoro J, Sastre J, Jauregui I, Bartra J, Davila I, Del Cuvillo A, Ferrer M, Mullol J, Valero A: Allergic rhinitis: continuous or on demand antihistamine therapy? J Investig Allergol Clin Immunol 2007, 17(Suppl 2):21-27.

4. Broide DH: Allergic rhinitis: Pathophysiology. Allergy Asthma Proc 2010, 31:370-374

5. Skoner DP: Allergic rhinitis: definition, epidemiology, pathophysiology, detection, and diagnosis. J Allergy Clin Immunol 2001, 108:S2-S8.

6. Rondon C, Campo P, Togias A, Fokkens WJ, Durham SR, Powe DG, Mullol J, Blanca M: Local allergic rhinitis: concept, pathophysiology, and management. J Allergy Clin Immunol 2012, 129:1460-1467.

7. Galli SJ, Tsai M, Piliponsky AM: The development of allergic inflammation. Nature 2008, 454:445-454.

8. Pawankar R, Mori S, Ozu C, Kimura S: Overview on the pathomechanisms of allergic rhinitis. Asia Pac allergy 2011, 1:157-167.

9. Shiraishi Y, Jia Y, Domenico J, Joetham A, Karasuyama H, Takeda K, Gelfand EW: Sequential engagement of FcepsilonRI on Mast Cells and Basophil Histamine H(4) Receptor and FcepsilonRI in Allergic Rhinitis. J Immunol 2013, 190:539-548.

10. Min B: Basophils: what they 'can do' versus what they 'actually do'. Nature immunology 2008, 9:1333-1339.

11. Bochner BS: Systemic activation of basophils and eosinophils: markers and consequences. J Allergy Clin Immunol 2000, 106:S292-S302.
12. Suzukawa M, Hirai K, likura M, Nagase $H$, Komiya A, Yoshimura-Uchiyama C, Yamada H, Ra C, Ohta K, Yamamoto K, Yamaguchi M: IgE- and FcepsilonRImediated migration of human basophils. Int Immunol 2005, 17:1249-1255.

13. Sanz ML, Sanchez G, Gamboa PM, Vila L, Uasuf C, Chazot M, Dieguez I, De Weck AL: Allergen-induced basophil activation: CD63 cell expression detected by flow cytometry in patients allergic to Dermatophagoides pteronyssinus and Lolium perenne. Clin Exp Allergy 2001, 31:1007-1013.

14. Lund G, Jacobi H, Skov PS, Holm J, Lund K: Effect on cell surface markers following allergen-induced desensitization of human whole-blood basophils. Int Arch Allergy Immunol 2010, 153:323-334.

15. Prussin C, Metcalfe DD: 5 . lgE, mast cells, basophils, and eosinophils. J Allergy Clin Immunol 2006, 117:S450-S456.

16. Packard KA, Khan MM: Effects of histamine on Th1/Th2 cytokine balance. Int Immunopharmacol 2003, 3:909-920.

17. Ogasawara M, Yamauchi K, Satoh Y, Yamaji R, Inui K, Jonker JW, Schinkel AH, Maeyama $K$ : Recent advances in molecular pharmacology of the histamine systems: organic cation transporters as a histamine transporter and histamine metabolism. J Pharmacol Sci 2006, 101:24-30.

18. Dy M, Schneider E: Histamine-cytokine connection in immunity and hematopoiesis. Cytokine Growth Factor Rev 2004, 15:393-410.

19. Bahceciler NN, Galip N: Comparing subcutaneous and sublingual immunotherapy: what do we know? Curr Opin Allergy Clin Immunol 2012, 12:640-647.

20. Cappella A, Durham SR: Allergen immunotherapy for allergic respiratory diseases. Hum Vaccin immunotherapeutics 2012, 8:1499-1512.

21. Moote W, Kim H: Allergen-specific immunotherapy. Allergy Asthma Immunol 2011, 7 Suppl 1:S5.

22. Jutel M, Akdis CA: Immunological mechanisms of allergen-specific immunotherapy. Allergy 2011, 66:725-732.

23. Shim JY, Kim BS, Cho SH, Min KU, Hong SJ: Allergen-specific conventional immunotherapy decreases immunoglobulin E-mediated basophil histamine releasability. Clin Exp Allergy 2003, 33:52-57.

24. Cady CT, Powell MS, Harbeck RJ, Giclas PC, Murphy JR, Katial RK, Weber RW, Hogarth PM, Johnson S, Bonvini E, et al: IgG antibodies produced during subcutaneous allergen immunotherapy mediate inhibition of basophil activation via a mechanism involving both FcgammaRIIA and FcgammaRIIB. Immunology letters 2010, 130:57-65.

25. Bousquet J, Schunemann HJ, Samolinski B, Demoly P, Baena-Cagnani CE, Bachert C, Bonini S, Boulet LP, Bousquet PJ, Brozek JL, et al: Allergic Rhinitis and its Impact on Asthma (ARIA): achievements in 10 years and future needs. J Allergy Clin Immunol 2012, 130:1049-1062.

26. Bousquet J: Global initiative for asthma (GINA) and its objectives. Clin Exp Allergy 2000, 30(Suppl 1):2-5.

27. Pereira C, Loureiro G, Martinho A, Paiva A, Tavares B, Machado D, Nunes R, Pedreira S, Henriques A, Pais ML, Segorbe-Luis A: T cell receptor excision circles (TREC) and recent thymic migrant cells in specific immunotherapy and respiratory allergy to Dermatophagoides pteronyssinus. Eur Ann Allergy Clin Immunol 2012, 44:61-72.

28. Han X, Jorgensen JL, Brahmandam A, Schlette E, Huh YO, Shi Y, Awagu S, Chen W: Immunophenotypic study of basophils by multiparameter flow cytometry. Arch Pathol Lab Med 2008, 132:813-819.

29. Vandesompele J, De Preter K, Pattyn F, Poppe B, Van Roy N, De Paepe A Speleman F: Accurate normalization of real-time quantitative RT-PCR data by geometric averaging of multiple internal control genes. Genome biology 2002, 3:RESEARCH0034.

30. Calderon MA, Demoly P, Gerth Van Wijk R, Bousquet J, Sheikh A, Frew A, Scadding G, Bachert C, Malling HJ, Valenta R, et al: EAACl: A European Declaration on Immunotherapy. Designing the future of allergen specific immunotherapy. Clin Trans/ Sci allergy 2012, 2:20.

31. Jutel M, Akdis M, Budak F, Aebischer-Casaulta C, Wrzyszcz M, Blaser K, Akdis CA: IL-10 and TGF-beta cooperate in the regulatory T cell response to mucosal allergens in normal immunity and specific immunotherapy. Eur J Immunol 2003, 33:1205-1214.

32. Uermosi C, Beerli RR, Bauer M, Manolova V, Dietmeier K, Buser RB, Kundig TM, Saudan P, Bachmann MF: Mechanisms of allergen-specific desensitization. J Allergy Clin Immunol 2010, 126:375-383.

33. Akdis $M$, Akdis CA: Mechanisms of allergen-specific immunotherapy. J Allergy Clin Immunol 2007, 119:780-791. 
34. Klimek L, Wolf H, Mewes T, Dormann D, Reske-Kunz A, Schnitker J, Mann W: The effect of short-term immunotherapy with molecular standardized grass and rye allergens on eosinophil cationic protein and tryptase in nasal secretions. J Allergy Clin Immunol 1999, 103:47-53.

35. Nullens S, Sabato V, Faber M, Leysen J, Bridts CH, De Clerck LS, Falcone FH, Maurer M, Ebo DG: Basophilic histamine content and release during venom immunotherapy: insights by flow cytometry. Cytometry Part $B$, Clinical cytometry 2013, 84:173-178.

36. Gauvreau GM, Lee JM, Watson RM, Irani AM, Schwartz LB, O'Byrne PM: Increased numbers of both airway basophils and mast cells in sputum after allergen inhalation challenge of atopic asthmatics. Am J Respir Crit Care Med 2000, 161:1473-1478.

37. Falcone $\mathrm{FH}$, Haas H, Gibbs BF: The human basophil: a new appreciation of its role in immune responses. Blood 2000, 96:4028-4038.

38. Denburg JA, Van Eeden SF: Bone marrow progenitors in inflammation and repair: new vistas in respiratory biology and pathophysiology. Eur Respir J 2006, 27:441-445.

39. Stone KD, Prussin C, Metcalfe DD: IgE, mast cells, basophils, and eosinophils. J Allergy Clin Immunol 2010, 125:S73-S80.

40. Kawakami T, Galli SJ: Regulation of mast-cell and basophil function and survival by lgE. Nature reviews Immunology 2002, 2:773-786.

41. Kubo S, Matsuoka K, Taya C, Kitamura F, Takai T, Yonekawa H, Karasuyama H: Drastic up-regulation of Fcepsilonri on mast cells is induced by $\lg \mathrm{E}$ binding through stabilization and accumulation of Fcepsilonri on the cell surface. J Immunol 2001, 167:3427-3434.

42. Pevec B, Radulovic Pevec M, Stipic Markovic A, Batista I, Rijavec M, Silar M, Kosnik M, Korosec P: House dust mite-specific immunotherapy alters the basal expression of T regulatory and FcepsilonRI pathway genes. Int Arch Allergy Immunol 2012, 159:287-296.

43. Rajakulasingam K, Durham SR, O'Brien F, Humbert M, Barata LT, Reece L, Kay AB, Grant JA: Enhanced expression of high-affinity lgE receptor (FC epsilon RI) alpha chain in human allergen-induced rhinitis with colocalization to mast cells, macrophages, eosinophils, and dendritic cells. J Allergy Clin Immunol 1997, 100:78-86.

44. Di Lorenzo G, Mansueto P, Pacor ML, Rizzo M, Castello F, Martinelli N, Ditta V, Lo Bianco C, Leto-Barone MS, D'Alcamo A, et al: Evaluation of serum s-lgE/total IgE ratio in predicting clinical response to allergenspecific immunotherapy. J Allergy Clin Immunol 2009, 123:1103-1110. 1110 e1101-1104

45. Jayasekera NP, Toma TP, Williams A, Rajakulasingam K: Mechanisms of immunotherapy in allergic rhinitis. Biomed Pharmacother 2007, 61:29-33.

46. Hirata N, Takeuchi K, Ukai K, Sakakura Y: Expression of histidine decarboxylase messenger RNA and histamine N-methyltransferase messenger RNA in nasal allergy. Clin Exp Allergy 1999, 29:76-83.

47. Jutel M, Muller UR, Fricker M, Rihs S, Pichler WJ, Dahinden C: Influence of bee venom immunotherapy on degranulation and leukotriene generation in human blood basophils. Clin Exp Allergy 1996, 26:1112-1118.

48. Jutel $M$, Blaser $K$, Akdis CA: Histamine receptors in immune regulation and allergen-specific immunotherapy. Immunol Allergy Clin North Am 2006, 26:245-259. vii.

49. Novak N, Mete N, Bussmann C, Maintz L, Bieber T, Akdis M, Zumkehr J, Jutel M, Akdis C: Early suppression of basophil activation during allergenspecific immunotherapy by histamine receptor 2. J Allergy Clin Immunol 2012, 130:1153-1158. e1152.

50. Pichler CE, Helbling A, Pichler WJ: Three years of specific immunotherapy with house-dust-mite extracts in patients with rhinitis and asthma: significant improvement of allergen-specific parameters and of nonspecific bronchial hyperreactivity. Allergy 2001, 56:301-306

51. Siegmund R, Vogelsang H, Machnik A, Herrmann D: Surface membrane antigen alteration on blood basophils in patients with Hymenoptera venom allergy under immunotherapy. J Allergy Clin Immunol 2000, 106:1190-1195.
52. Krishna MT, Huissoon AP: Clinical immunology review series: an approach to desensitization. Clin Exp Immunol 2011, 163:131-146.

53. Larson D, Hubner MP, Torrero MN, Morris CP, Brankin A, Swierczewski BE, Davies SJ, Vonakis BM, Mitre E: Chronic helminth infection reduces basophil responsiveness in an IL-10-dependent manner. J Immunol 2012, 188:4188-4199.

doi:10.1186/1710-1492-9-40

Cite this article as: Lopes et al:: Impact of allergic rhinitis and specific subcutaneous immunotherapy on peripheral blood basophils of patients sensitized to Dermatophagoides pteronyssinus. Allergy, Asthma \& Clinical Immunology 2013 9:40.

\section{Submit your next manuscript to BioMed Central and take full advantage of:}

- Convenient online submission

- Thorough peer review

- No space constraints or color figure charges

- Immediate publication on acceptance

- Inclusion in PubMed, CAS, Scopus and Google Scholar

- Research which is freely available for redistribution

Submit your manuscript at www.biomedcentral.com/submit
C) BioMed Central 